\title{
Produção de Ácido D-Lático por Rota Fermentativa e Hidrólise Enzimática a partir de Matéria-Prima Lignocelulósica
}

\author{
Mateus K. Rodrigues, Michelle Reich, Flávia D. Pimenta. \& Marta C. Picardo
}

O presente trabalho estuda o processo de produção de ácido lático a partir de biomassa lignocelulósica. Com auxílio do software Microsoft Excel, foi realizado o balanço material a fim de se obter o rendimento global do processo. Foi realizado estudo de cenários alternativos para avaliar o impacto do rendimento da etapa de hidrólise enzimática no rendimento global e parcial (considerando apenas a fração celulósica) em ácido lático. O melhor rendimento em ácido lático a partir de bagaço de cana, quando só a fração celulósica da biomassa é considerada, equivale a $84,74 \%$.

Palavras-chave: ácido lático; balanço material; matéria-prima lignocelulósica.

The present work studies the lactic acid production process based on lignocellulosic biomass. Material balance relative to the stages of production was made to calculate the global yield of the process. Scenario Manager was used to evaluate the impact of the enzymatic hydrolysis efficiency in the global yield. The best yield regarding only the cellulosic fraction of the biomass achieved using sugarcane bagasse as feedstock was $84.74 \%$.

Keywords: lactic acid; material balance; lignocellulosic feedstock. 


\section{Introdução}

Os bioprocessos, de forma geral, são caracterizados por apresentarem soluções inovadoras para a produção de substâncias químicas e processos mais limpos. Vários dos conceitos de Biotecnologia definidos se referem ao uso de elementos orgânicos vivos em processos de produção de bens ou de prestação de serviços ${ }^{1}$. Entre os produtos que são de possível obtenção por estes meios, destaca-se o ácido lático.

$\mathrm{O}$ ácido lático pode dar origem a diversas moléculas de interesse industrial, entre elas, o PLA, o ácido propiônico e o propilenoglicol. Por apresentar essa característica, é comum denominá-lo como um "bloco de construção". Além de sua aplicabilidade como ácido lático em si, suas derivações também justificam sua produção em grande escala. É um ácido orgânico de grande importância no setor industrial, principalmente, nos setores farmacêutico, de alimentos, de cosméticos, de polímeros, de metais galvanizados, petrolífero, têxtil e agroquímico. O setor que apresenta maior crescimento na demanda de ácido lático é o de polímeros devido ao seu uso como monômero para a produção de poli (ácido lático), também chamado de PLA ${ }^{2}$.

$\mathrm{O}$ uso de resíduos provenientes da agricultura e do setor agroindustrial, ambos de composição lignocelulósica, são de grande interesse e relevância para a Biotecnologia Moderna, uma vez que não dependem da expansão territorial da área de cultivo. A maior parte da biomassa residual gerada no Brasil provém da cana-de-açúcar ${ }^{1}$.

Tendo em vista o interesse industrial no uso de biomassa residual como matéria-prima e o extenso portfólio de produtos derivados do ácido lático, o presente trabalho propõe um processo de produção do ácido D-lático a partir de material lignocelulósico. Inicialmente, o bagaço de cana foi utilizado como matéria-prima, porém, um estudo foi feito para avaliar o emprego de outros tipos de biomassas. O rendimento do processo foi obtido por meio do balanço material e a capacidade produtiva da planta proposta será avaliada conforme comparação com outras unidades produtoras.

\section{Metodologia}

A composição mássica do bagaço de cana utilizada para fazer o balanço de massa principal é uma média das composições relatadas por Silva ${ }^{3}$ e Souza ${ }^{4}$. As cinzas e os extrativos não foram levados em consideração no balanço de massa, em razão de serem vistos como inertes. A composição média pode ser observada na Tabela 1.

Tabela 1. Composição da biomassa (\% em massa)

\begin{tabular}{|c|c|}
\hline Celulose & $45,3 \%$ \\
\hline Hemicelulose & $29,2 \%$ \\
\hline Lignina & $19,2 \%$ \\
\hline
\end{tabular}

Os resultados dos balanços de massa das etapas do processo foram descritos e analisados com base nessa composição. Posteriormente, os valores obtidos foram comparados a outros tipos de biomassas lignocelulósicas para isso, fez-se o uso da ferramenta "Gerenciamento de Cenários" do software Microsoft Excel.

Visto que o trabalho visa à obtenção do rendimento global, não foram levados em consideração os balanços energéticos. Os processamentos da fração hemicelulósica e da lignina não foram abordados no balanço de massa. Um fluxograma de processo foi feito no software SuperPro Designer. Nele, estão representadas as etapas de prétratamento, hidrólise, fermentação e eletrodiálise. Os cálculos referentes ao balanço de massa foram realizados mediante auxílio da plataforma Microsoft Excel.

\section{PRÉ-TRATAMENTO ÁCIDO}

Dentre as opções de pré-tratamento ácido se optou pelo tratamento químico com ácido dilúido. Este processo apresenta vantagens em relação a tratamentos que não são catalisados porque permitem a formação de uma fase líquida (hidrolisado hemicelulósico) rico em xilose ${ }^{5}$.

A biomassa é submetida a um pré-tratamento físico anterior à etapa efetiva de pré-tratamento com ácido diluído. O pré-tratamento físico consiste na cominuição da biomassa através de um moinho de facas de modo a facilitar 
as etapas posteriores. A biomassa, então, é direcionada à um reator alimentado com ácido clorídrico em que ocorrerá a remoção parcial da fração hemicelulósica, de modo a hidrolisá-la.

As condições para o pré-tratamento ácido foram definidas com base na pesquisa desenvolvida por Betancur ${ }^{5}$. Tais condições são: relação sólido/líquido (S:L) de 1/2,8 (g/ $\mathrm{ml}$ ), tempo de exposição de 27 minutos e temperatura de $121^{\circ} \mathrm{C}$. O rendimento em relação à hidrólise da hemicelulose obtido experimentalmente por Betancur ${ }^{5}$ através dessas condições foi de $60,24 \%$.

A corrente proveniente do reator passa por um processo de prensagem e lavagem (filtro-prensa) durante 120 minutos, até que se retire a fração hemicelulósica e que se garanta a remoção dos compostos presentes nos interstícios da celulignina ${ }^{6}$. Ao ser processada pelo filtro-prensa, a celulignina (parte sólida) é enviada para a etapa de pré-tratamento básico, enquanto a hemicelulose hidrolisada pode ser armazenada ou seguir para outra unidade de processamento, visto que apresenta xilose em sua composição, açúcar de grande importância para a área biotecnológica ${ }^{7}$.

Como visto anteriormente, o pré-tratamento ácido se propõe a remover parte da hemicelulose da biomassa. Espera-se, então, que a porcentagem de hemicelulose na biomassa após o processo seja menor.

Essa etapa é ilustrada pela Figura 1 e apresenta duas correntes de entrada, a corrente "Biomassa" e a corrente "HCl", que contém a biomassa lignocelulósica e o ácido clorídrico, respectivamente. Após ser processada pelo filtro-prensa, essa corrente se desmembrará em uma fração líquida, que contém hemicelulose hidrolisada e a fração sólida de nome "Celulignina".

Para determinar o quanto de hemicelulose está presente na corrente "Hidrolisado Hemicelulósico" foi realizado o seguinte cálculo:

Quantidade de Hemicelulose Hidrolisada $=$ Quantidade de Biomassa $\mathrm{x}$ Fração de Hemicelulose $\mathrm{x}$ Rendimento

\section{Pré-tratamento Ácido}

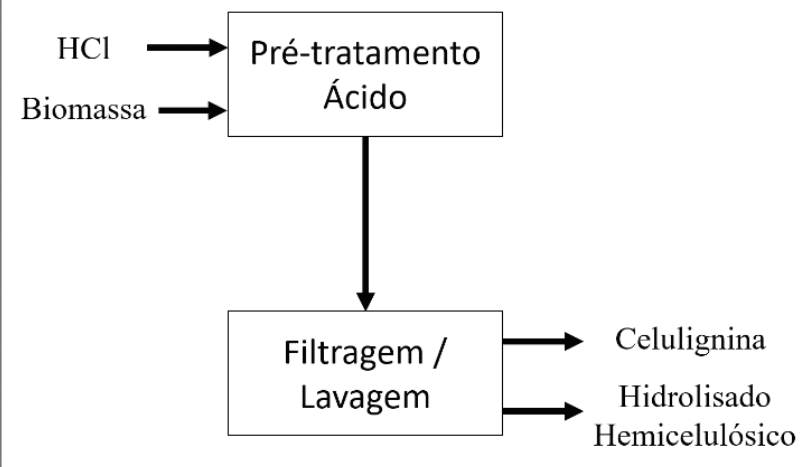

Figura 1. Diagrama de blocos da etapa de pré-tratamento ácido.

Para calcular a quantidade de hemicelulose ainda presente na biomassa após essa etapa de pré-tratamento, é necessário subtrair a quantidade de hidrolisado pela quantidade inicial de hemicelulose presente na biomassa. As quantidades de celulose e lignina não se alteram, visto que não são removidas de forma substancial por este pré-tratamento.

Em relação à massa necessária de ácido clorídrico, como a proporção está definida em percentual peso/peso, o cálculo foi o seguinte:

Quantidade Necessária de HCI

= Quantidade de Biomassa x Produção de HCI

\section{PRÉ-TRATAMENTO BÁSICO}

A corrente proveniente do pré-tratamento ácido é direcionada para a etapa de deslignificação, também chamada de pré-tratamento básico. Nele, parte da lignina é removida da biomassa de modo a facilitar a ação das enzimas na etapa de hidrólise enzimática. Essa etapa é realizada em um reator alimentado por uma corrente de hidróxido de sódio, em que ocorre a solubilização parcial da lignina presente na biomassa.

A concentração de $\mathrm{NaOH}$ na etapa do pré-tratamento básico foi definida de acordo com os estudos realizados por Rezende ${ }^{8}$, mantendo a temperatura da etapa de prétratamento ácido $\left(120^{\circ} \mathrm{C}\right)$ por 30 minutos. Os resultados 
obtidos mostraram que, ao usar concentrações de hidróxido de sódio de no mínimo $1 \%(\mathrm{~m} / \mathrm{v})$, obtém-se rendimento de $85 \%$ em relação à remoção de lignina.

Após o processo de deslignificação, a corrente de saída é enviada a um filtro rotativo a vácuo e a lignina solubilizada é direcionada para uma etapa de concentração (não descrita nesse trabalho), enquanto a fração sólida, composta em sua maior parte de celulose, é enviada à etapa de hidrólise enzimática. A operação de filtração do filtro rotativo a vácuo tem duração de 120 minutos. A fração sólida resultante desse processo de pré-tratamento é denominada como "Celulignina Parcialmente Deslignificada" (CPD). Essa etapa está representada pela Figura 2 e apresenta, como entrada principal, a corrente "Celulignina" proveniente do pré-tratamento ácido. O hidróxido de sódio necessário para o processo de deslignificação é introduzido através da corrente "NaOH". Após a filtragem, as correntes se dividem em fração sólida, chamada de "Celulignina Parcialmente Deslignificada (CPD)" e fração líquida, composta pela lignina removida da biomassa.

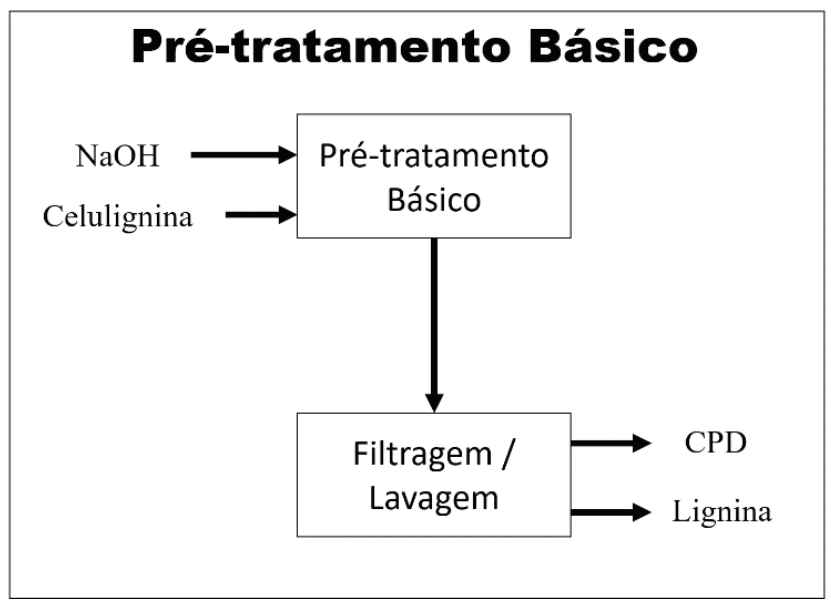

Figura 2. Diagrama de blocos da etapa de pré-tratamento básico.

Como descrito por Rezende ${ }^{8}$, esse processo apresenta rendimento de $85 \%$ em relação à remoção da lignina presente na biomassa. Para determinar o quanto de lignina foi removida, foi realizado o seguinte cálculo:

Quantidade de Lignina Removida

$=$ Quantidade de Celulignina $\mathrm{x}$ Fração da Lignina $\mathrm{x}$ Rendimento
Para calcular a quantidade de lignina ainda presente na biomassa após essa etapa de pré-tratamento, é necessário subtrair a quantidade removida pela quantidade inicial de lignina presente na celulignina. As quantidades de celulose e hemicelulose não se alteram, visto que não são removidas de forma substancial por este pré-tratamento.

Em relação à quantidade necessária de hidróxido de sódio, como a proporção está definida em percentual peso/ volume, primeiro é necessário calcular o volume de água necessário para o processo. Para o processo em questão, a relação entre sólidos e líquido definida foi de 1:4, portanto, para calcular a quantidade necessária de água, transformouse a unidade da quantidade de biomassa de toneladas para quilogramas e, seguindo a proporção, multiplicou-se esse número por 4.

Após mensurada a quantidade de água necessária, calculou-se a massa de hidróxido de sódio exigida por meio da seguinte equação:

Quantidade Necessária de $\mathrm{NaOH}$

$=$ Quantidade de Água $x$ Proporção do $\mathrm{NaOH}$

\section{HIDRÓLISE ENZIMÁTICA}

Após as etapas de pré-tratamento, a biomassa tratada (CPD) é endereçada à hidrólise enzimática. Além da corrente proveniente da biomassa, o reator é alimentado pelas enzimas que realizam a hidrólise da celulose em glicose.

A etapa de hidrólise é baseada no trabalho de Méndez Arias et al. ${ }^{9}$ em que uma mistura otimizada de enzimas produzidas pelos fungos Trichoderma harzianum, Penicillium funiculosum e Aspergillus niger foi desenvolvida. Utilizando essa mistura, atingiu-se um rendimento de hidrólise de $91 \%$ após 48h de reação enzimática.

As condições para a hidrólise enzimáticas foram definidas por Méndez Arias et al. ${ }^{9}$ e consistem em uma carga enzimática de $10 \mathrm{mg}$ /gcelulose, $\mathrm{pH}$ 5, relação sólido/ líquido de 1:4 e uma temperatura de $50^{\circ} \mathrm{C}$. A corrente resultante do processo é rica em glicose e é enviada à etapa de Fermentação. Denomina-se essa corrente de "Hidrolisado Celulósico". 
Após as etapas de pré-tratamento, a corrente de biomassa tratada (CPD) é direcionada para a etapa de hidrólise. O reator de hidrólise também é alimentado pelas enzimas que atuarão no processo. A corrente resultante dessa etapa é denominada "Hidrolisado Celulósico" e contém açúcares provenientes da hidrólise da celulose. A Figura 3 ilustra a etapa de hidrólise enzimática.

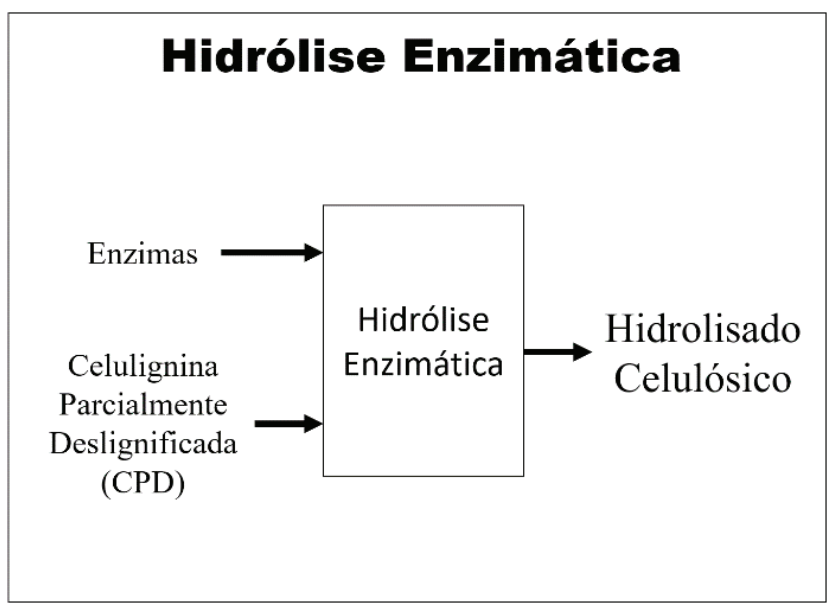

Figura 3. Diagrama de blocos da etapa de hidrólise enzimática.

A carga enzimática definida para esta etapa é de 10 $\mathrm{mg} / \mathrm{gcelulose}$, sendo essa celulose a provida pela CPD. É possível, então, por meio da composição da biomassa obtida na etapa anterior, quantificar, em massa, a quantidade de enzimas necessárias. $\mathrm{O}$ rendimento desse processo ao utilizar uma mistura enzimática desenvolvida por Méndez Arias et al. ${ }^{9}$ foi de $91 \%$. Para calcular a quantidade de celulose hidrolisada, realizou-se o seguinte cálculo:

Quantidade de Celulose Hidrolisada

$=$ Quantidade de CPD x Fração da Celulose na CPD x Rendimento

\section{FERMENTAÇÃO}

A etapa de fermentação recebe a corrente de hidrolisado celulósico da etapa de hidrólise enzimática e é alimentada com os nutrientes necessários para o crescimento e ação dos microrganismos. A bactéria Lactobacillus coryniformis torquens processa a glicose proveniente da hidrólise da celulose na etapa anterior em ácido lático. Como a fermentação acontece em um pH fixo, uma solução de $\mathrm{NaOH}$ é adicionada ao meio para controlá-lo. A adição de $\mathrm{NaOH}$ tem como consequência a formação de lactato de sódio, sal derivado do ácido lático produzido ${ }^{10}$.

A etapa de fermentação é mantida em $37^{\circ} \mathrm{C}, \mathrm{pH} 6,5$ e tem duração de $24 \mathrm{~h}$ como fora determinado por Moraes ${ }^{11}$. Será necessária a adição do meio MRS sem presença de glicose no biorreator para o desenvolvimento do microrganismo, a glicose será provida pelo hidrolisado celulósico.

A etapa de fermentação apresenta quatro correntes de entrada: a corrente proveniente da etapa de hidrólise, uma corrente que contém os nutrientes necessários para a fermentação, uma corrente que contém hidróxido de sódio para ajustar o $\mathrm{pH}$ e, por fim, uma corrente que contém as bactérias fermentadoras. A etapa de fermentação é ilustrada pela Figura 4.

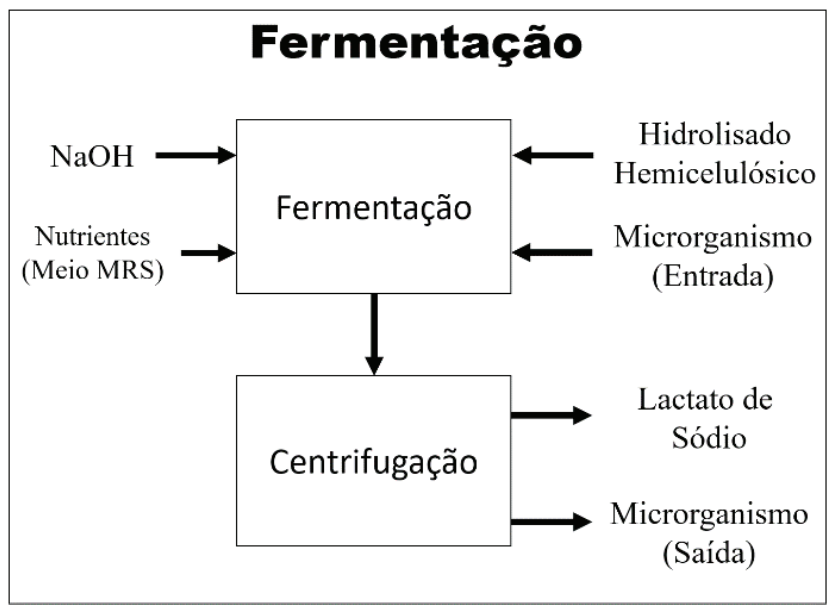

Figura 4. Diagrama de blocos da etapa de fermentação.

Antes de realizar os cálculos de balanço de massa, a estequiometria do processo precisou ser definida. O microrganismo é capaz de processar a glicose de modo que, para cada grama de substrato, é produzido $0,97 \mathrm{~g}$ de ácido lático ${ }^{11}$. A estequiometria para essa transformação é a seguinte:

$$
\mathrm{C}_{6} \mathrm{H}_{12} \mathrm{O}_{6} \rightarrow 2 \mathrm{C}_{3} \mathrm{H}_{6} \mathrm{O}_{3}
$$


$\mathrm{O}$ pH do sistema tende a cair conforme moléculas de ácido lático são formadas, para mantê-lo estável é necessária a adição de hidróxido de sódio. Essa adição resulta na formação de lactato de sódio, considerou-se que essa reação apresenta rendimento ideal. Tratando-se de uma reação de neutralização simples, a estequiometria é a seguinte:

$$
\mathrm{C}_{3} \mathrm{H}_{6} \mathrm{O}_{3}+\mathrm{NaOH} \rightarrow \mathrm{C}_{3} \mathrm{H}_{5} \mathrm{O}_{3} \mathrm{Na}+\mathrm{H}_{2} \mathrm{O}
$$

A partir da associação entre as duas estequiometrias, é possível calcular a quantidade de lactato de sódio produzido ao final do processo e a quantidade necessária de hidróxido de sódio. A corrente de saída é direcionada para uma centrífuga, em que são separados os microrganismos do sobrenadante.

A quantidade de nutrientes necessários pode ser calculada por meio da concentração do meio MRS (sem glicose) e do volume útil do fermentador, conforme a seguinte equação:

$$
\text { Massa }=\text { Concentração } \mathrm{x} \text { Volume Útil }
$$

A partir da Equação 8, é possível calcular a quantidade necessária de cada componente do meio de forma separada.

\section{ELETRODIÁLISE}

Dentre os processos de recuperação do ácido lático optou-se pela eletrodiálise. A eletrodiálise é um processo eficiente e limpo quando comparado a outros métodos de recuperação de ácido lático utilizados, visto que não há produção de sal como subproduto ${ }^{12}$.

Essa etapa visa recuperar o ácido lático transformado em lactato de sódio na etapa de fermentação. No final do processo, espera-se ter uma corrente de saída de ácido lático e outra de hidróxido de sódio.

Dentre os processos de eletrodiálise descritos pela literatura, o desenvolvido por Kim \& Moon ${ }^{10}$ se destaca por apresentar taxa de recuperação de $96 \%$ em relação à recuperação do ácido lático e $93 \%$ em relação ao hidróxido de sódio.

O sobrenadante resultante da etapa de fermentação seguirá para a etapa de eletrodiálise, em que foram obtidos, em duas correntes separadas, o ácido lático e o hidróxido de sódio. Essa etapa está representada pela Figura 5.

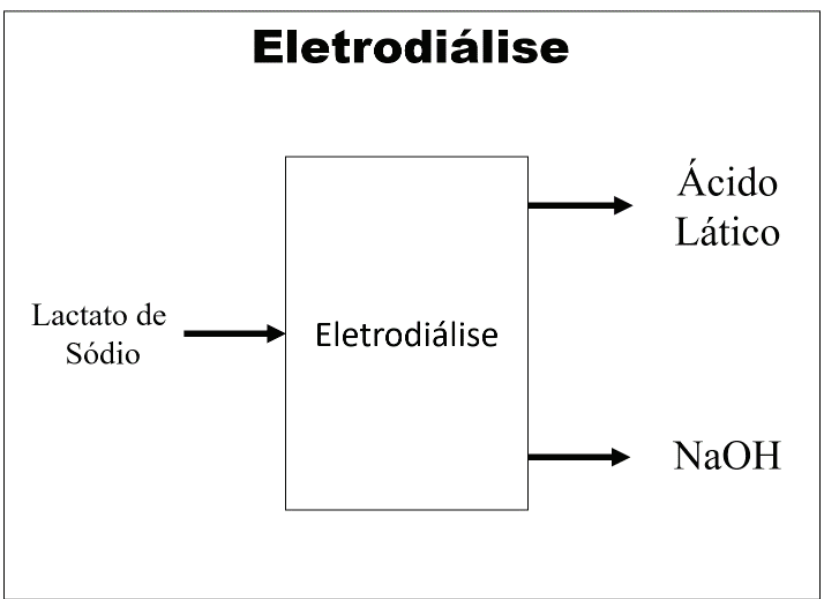

Figura 5. Diagrama de blocos da etapa de eletrodiálise.

A estequiometria para essa etapa é inversa à formação de lactato de sódio na etapa de fermentação, e descrita a seguir:

$$
\mathrm{C}_{3} \mathrm{H}_{5} \mathrm{O}_{3} \mathrm{Na}+\mathrm{H}_{2} \mathrm{O} \rightarrow \mathrm{C}_{3} \mathrm{H}_{6} \mathrm{O}_{3}+\mathrm{NaOH}
$$

Conforme Kim \& Moon $^{10}$, a taxa de recuperação do $\mathrm{NaOH}$ desse processo é de $93 \%$, já a de ácido lático é de $96 \%$. Para calcular as quantidades recuperadas de ambos os compostos é preciso realizar os cálculos estequiométricos e levar em consideração a taxa de recuperação de cada composto.

\section{CÁLCULO DE RENDIMENTO}

Por meio do balanço de massa do processo, será possível saber a quantidade de ácido lático produzido e, ao relaciona-lo com a biomassa utilizada inicialmente, obtém-se o rendimento global do processo, conforme a seguinte equação:

Rendimento Global do Processo $=\frac{\text { Ácido Lático Produzido }}{\text { Biomassa Utilizada }}$

$\mathrm{O}$ cálculo do rendimento somente relacionado à quantidade de celulose presente na biomassa foi obtido 
or meio da Equação 11. Nela, relacionamos a quantidade total de ácido lático produzido, com a fração celulósica da biomassa.

$$
\text { Rendimento }(\text { Celulose })=\frac{\text { Ácido Lático Produzido }}{\text { Biomassa x Fração Celulósica }}
$$

\section{GERENCIAMENTO DE CENÁRIOS}

A ferramenta "Gerenciamento de Cenários" Microsoft Excel permite a criação de vários cenários alternativos, possibilitando analisar como a composição de diferentes tipos de biomassa lignocelulósica afetaria o rendimento global do processo. Para cada cenário, os valores de composição são alterados, porém, a estrutura do balanço de massa se mantém. Uma gama de cenários foi idealizada abrangendo composições dos diferentes tipos de biomassa relatadas por Silva ${ }^{3}$. Essa ferramenta gera, como resposta, um relatório que contém o rendimento global atualizado para cada cenário empregado. A Tabela 2 exibe os cenários referentes às composições relatadas por Silva ${ }^{3}$. Em relação ao bagaço de cana, foi utilizada a média das composições descritas anteriormente.

A partir da obtenção desses dados, é possível realizar um levantamento de quais tipos de biomassa mais se adequam ao processo e analisar, individualmente, as correntes de saída dos outros subprodutos gerados, como o hidrolisado hemicelulósico e a lignina removida.

\section{Resultados e Discussões}

\section{PRÉ-TRATAMENTO ÁCIDO}

Foi definido, como base de cálculo, a utilização de 150 toneladas de biomassa inicial. Portanto, obedecendo a composição mássica definida anteriormente (Tabela 1) e analisando cada fração separadamente, a biomassa disponibiliza 67,95 toneladas de celulose, 43,95 toneladas de hemicelulose e 28,8 toneladas de lignina. A etapa de prétratamento ácido está representada pela Figura 6.

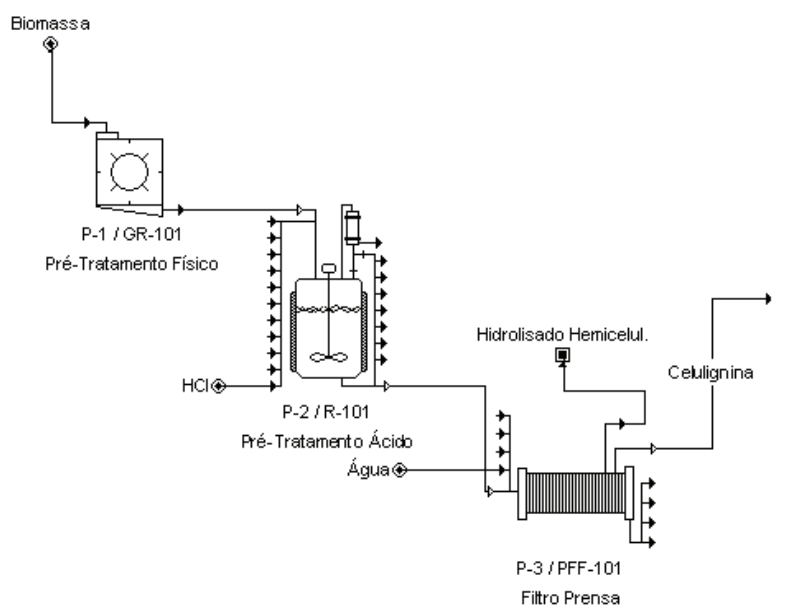

Figura 6. Fluxograma da etapa de pré-tratamento ácido.

Tabela 2. Gerenciamento de Cenários (Biomassa)

\begin{tabular}{|c|c|c|c|c|}
\hline Cenários & $\begin{array}{c}\text { Material } \\
\text { Lignocelulósico }\end{array}$ & Celulose (\%) & Hemicelulose (\%) & Lignina (\%) \\
\hline Cenário 1 & Farelo de cevada & 23 & 32,7 & 24,4 \\
\hline Cenário 2 & Sabugo de milho & 31,7 & 34,7 & 20,3 \\
\hline Cenário 3 & Folhas de milho & 37,6 & 34,5 & 12,6 \\
\hline Cenário 4 & Palha de arroz & 43,5 & 22 & 17,2 \\
\hline Cenário 5 & Palha de trigo & 33,8 & 31,8 & 20,1 \\
\hline Cenário 6 & Palha de sorgo & 34 & 44 & 20 \\
\hline Cenário 7 & Casca de aveia & 30,5 & 28,6 & 26,9 \\
\hline Cenário 8 & Eucalyptus grandis & 40,2 & 15,7 & 22,9 \\
\hline Cenário 9 & Eucalyptus globulus & 46,3 & 17,1 & 19,2 \\
\hline Cenário 10 & Bagaço de cana* & 45,3 & 29,3 & \\
\hline
\end{tabular}


Calculou-se que a quantidade de hemicelulose hidrolisada por este processo foi de 26,5 toneladas. Para esta etapa, são necessárias 3 toneladas de ácido clorídrico. Após a passagem pelo filtro-prensa, ocorre a separação entre fase sólida e fase líquida, representados, respectivamente, pelas correntes "Celulignina" e "Hidrolisado Hemicelulósico". A corrente "Hidrolisado Hemicelulósico" é composta pela quantidade de hemicelulose hidrolisada, ou seja, 26,5 toneladas. A corrente "Celulignina" é composta pelo restante da biomassa que não foi hidrolisada nessa etapa, totalizando 123,5 toneladas.

\section{PRÉ-TRATAMENTO BÁSICO}

A composição da biomassa proveniente da etapa de prétratamento ácido é de 67,95 toneladas de celulose, 17,47 toneladas de hemicelulose e 28,8 toneladas de lignina. Para a etapa de pré-tratamento básico, calculou-se o uso de 4,6 toneladas de hidróxido de sódio. Essa etapa está representada pela Figura 7.

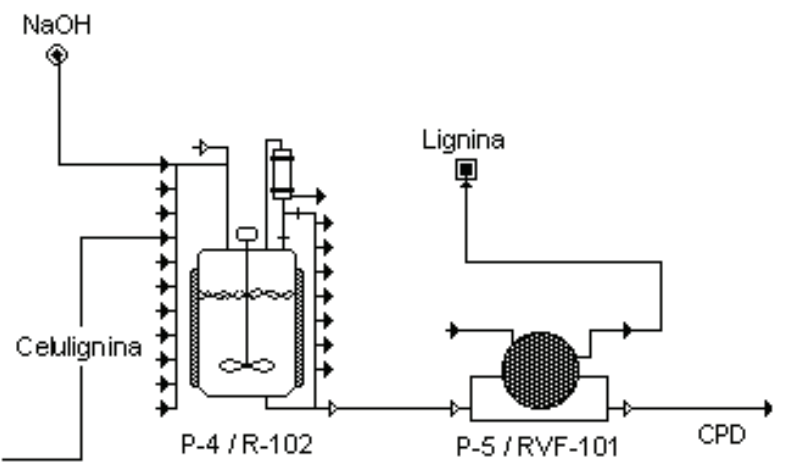

Pré-Tratamento Bá sico Filtro Rotativo à Vácuo

Figura 7. Fluxograma da etapa de pré-tratamento básico.

A quantidade de lignina removida por este processo foi de 24,5 toneladas das 28,8 toneladas presentes na celulignina. Assim como a etapa de pré-tratamento ácido, a corrente é separada em fração sólida e líquida após etapa de filtragem, representadas pelas correntes, "CPD" e "Lignina", respectivamente. A corrente "Lignina" é composta pela lignina solubilizada, totalizando 24,5 toneladas. A corrente "CPD" é composta pela biomassa após a etapa de pré-tratamento básico, ou seja, em massa, totaliza 89,7 toneladas.

\section{HIDRÓLISE ENZIMÁTICA}

A etapa de hidrólise enzimática recebe a corrente "CPD", resultante das etapas de pré-tratamento. Essa corrente é rica em celulose $(75,71 \%)$, componente que será hidrolisado em glicose, substrato da etapa de fermentação. A etapa de hidrólise enzimática está ilustrada na Figura 8.

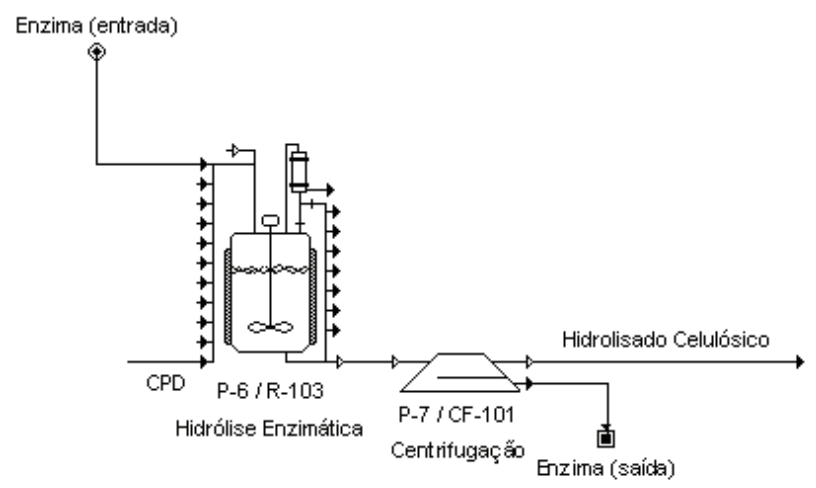

Figura 8. Fluxograma da etapa de hidrólise enzimática.

Analisada separadamente, a quantidade de celulose presente na corrente "CPD" corresponde a 67,95 toneladas. Considerando que a hidrólise atinja rendimento máximo, espera-se que $91 \%$ da celulose presente na biomassa seja hidrolisada, dessa maneira, a massa de glicose disponível na etapa de fermentação é de 61,8 toneladas. A quantidade necessária de carga enzimática para processar essa celulose corresponde a $680 \mathrm{~kg}$, obedecendo à razão da carga enzimática de $10 \mathrm{mg} /$ gcelulose relatada por Méndez et al. ${ }^{9}$.

O efeito da etapa de pré-tratamento é fundamental para que se obtenha um rendimento alto na etapa de hidrólise enzimática. Caso a hidrólise seja feita sem nenhum tipo de pré-tratamento, o rendimento, na maioria dos casos, não ultrapassa $20 \%$, porém, como consequência de uma biomassa tratada especialmente para essa etapa, é possível atingir rendimentos maiores que $90 \%{ }^{13}$.

\section{FERMENTAÇÃO}

A etapa de fermentação é responsável pela produção de ácido lático, contudo, incorpora-se hidróxido de sódio ao 
meio para regular seu $\mathrm{pH}$. Este procedimento ocasiona a formação de lactato de sódio, sal derivado do ácido lático. A etapa de fermentação está representada pela Figura 9.

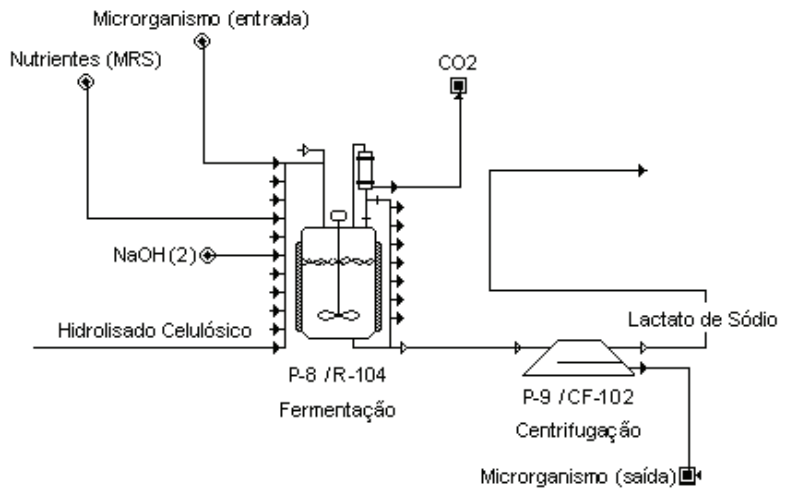

Figura 9. Fluxograma da etapa de fermentação.

O estudo feito por Moraes ${ }^{11}$ retrata concentração de 42,8 $\mathrm{g} / \mathrm{L}$ relativa à glicose presente no meio. Esse fator, associado à quantidade de glicose aplicada ao reator, imprime que o volume útil total da fermentação seja de, aproximadamente, $1450 \mathrm{~m}^{3}$. Para suportar esse volume, sugere-se o uso de 3 reatores de $500 \mathrm{~m}^{3}$.

As massas necessárias de cada componente do meio MRS, considerando volume total de $1450 \mathrm{~m}^{3}$, estão descritas na Tabela 3.

Tabela 3. Massas referentes ao meio MRS

\begin{tabular}{|c|c|}
\hline Componente & Massa (toneladas) \\
\hline Peptona & 14,4 \\
\hline Extrato de Carne & 14,4 \\
\hline Extrato de Levedura & 7,2 \\
\hline Polisorbato 80 & 1,4 \\
\hline Citrato de Amônio & 2,9 \\
\hline Acetado de Sódio & 7,2 \\
\hline Sulfato de Magnésio & 0,14 \\
\hline Sulfato de Manganês & 0,07 \\
\hline Fosfato Dipotássico & 2,9 \\
\hline
\end{tabular}

Levando em consideração um rendimento fermentativo de $0,97 \mathrm{~g} / \mathrm{gglicose}$, a massa de ácido lático produzida pelo microrganismo equivale a 59,98 toneladas. Por meio de cálculos estequiométricos, estimou-se a adição de 26,63 toneladas de hidróxido de sódio no fermentador. Estimouse, também, que a quantidade resultante de lactato de sódio que corresponde a 74,61 toneladas. $\mathrm{O}$ aumento da massa do produto final da etapa de fermentação se deve a incorporação do cátion $\mathrm{Na}+$, composto de alta massa atômica, na estrutura do ácido lático.

\section{ELETRODIÁLISE}

Para obtenção do ácido lático como produto final, é necessária uma etapa de recuperação. A corrente entregue ao equipamento de eletrodiálise contém, em sua maior parte, lactato de sódio. O processo de eletrodiálise visa recuperar o ácido lático e o hidróxido de sódio or meio da quebra da molécula de lactato de sódio e posterior recombinação com os íons H+e OH-. Essa etapa é ilustrada pela Figura 10.
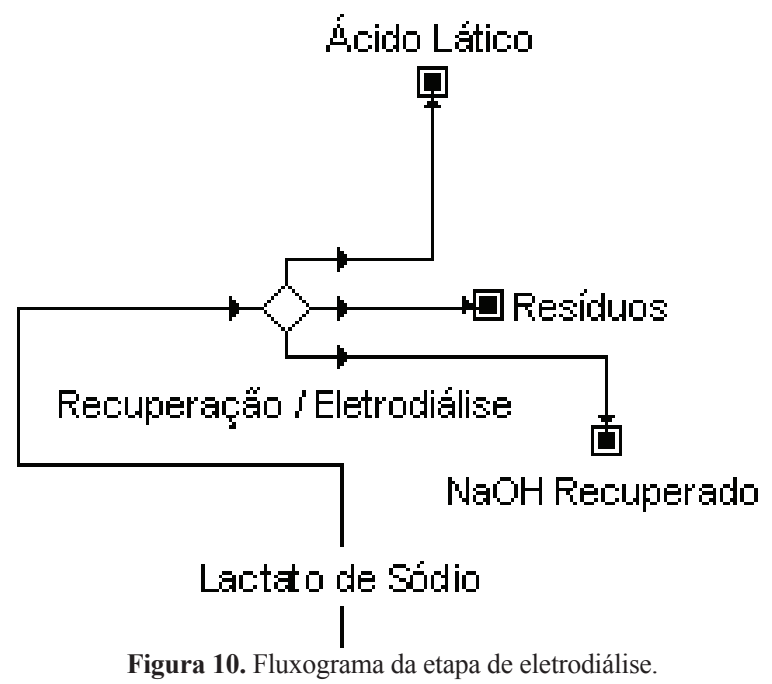

O rendimento desse processo, conforme Kim \& Moon $^{10}$, é de $96 \%$ em relação ao ácido lático e $93 \%$ em relação ao hidróxido de sódio. Por meio de cálculos estequiométricos, estimou-se que a quantidade de ácido lático e hidróxido de sódio recuperado corresponde a 57,6 e 24,8 toneladas, respectivamente. 


\section{RENDIMENTO AO FINAL DO PROCESSO}

Ao final do processo, foram produzidas 57,6 toneladas de ácido lático a partir de 150 toneladas de bagaço de cana, o que equivale a um rendimento global de 38,39\%. Esse rendimento foi calculado com base na quantidade total de biomassa inserida inicialmente no processo, incluindo as frações hemicelulósica e de lignina. Ambos os componentes, embora valiosos para outros processos, não configuram como substrato para a produção de ácido lático do presente trabalho, reduzindo, assim, o rendimento global relatado. Quando só a fração celulósica da biomassa é levada em consideração, o rendimento é de $84,74 \%$. Como subprodutos, foram obtidas 26,5 toneladas de hidrolisado hemicelulósico e 25,5 toneladas de lignina. O hidróxido de sódio recuperado na etapa de eletrodiálise pode ser reaproveitado na etapa de pré-tratamento básico e/ou na etapa de fermentação.

O tempo de processo total estimado foi de aproximadamente 77,8 horas. As etapas mais demoradas são as de hidrólise enzimática e fermentação, correspondendo a 48 e 24 horas, respectivamente. Esses tempos foram adotados a fim de se obter o maior rendimento possível, caso haja necessidade, pode-se reduzi-los a custo de um menor aproveitamento das etapas correspondentes.

Considerando um tempo de processo total de 77,8 horas, produção final de 57,6 toneladas de ácido lático e 5040 horas de funcionamento da planta no ano, estima-se capacidade produtiva anual de 3731,4 toneladas de ácido lático. Para efeito comparativo, a Tabela 4 exibe uma lista de alguns produtores mundiais de ácido lático.

Tabela 4. Produção mundial de ácido lático.

\begin{tabular}{|c|c|c|}
\hline Empresa & Capacidade Anual (t/ano) & Localização da Planta \\
\hline NatureWorks & 150.000 & Blair, Nebraska (EUA) \\
\hline NatureWorks & 150.000 & Tailândia ou Malásia \\
\hline Purac & 50.000 & Blair, Nebraska (EUA) \\
\hline Purac & 100.000 & Tailândia \\
\hline Purac & 35.000 & Brasil \\
\hline Purac & 55.000 & Espanha \\
\hline ADM & 30.000 & Decatur, Illinois (EUA) \\
\hline Cellulac & 100.000 & Irlanda \\
\hline Galactic & 15.000 & Milwaukee, Wisconsin (EUA) \\
\hline Galactic & 50.000 & Bengbu, China \\
\hline Futerro & 1.500 & Escanaffles, Bélgica \\
\hline ThyssenKrupp Industrial Solutions & 3.000 & Guben, Alemanha \\
\hline Synbra Technology & 1.000 & Suíça \\
\hline Synbra Technology & 5.000 & Etten-Leur, Holanda \\
\hline Musashino Chemical Laboratory, Ltd & 7.000 & Japão \\
\hline Henan Jindan Lactic Acid Technology Co., Ltd. & 200.000 & Província de Henan, China \\
\hline Zhejiang Hisun Chemical & 5.000 & Província de Zhejiang, China \\
\hline Nantong Jiuding Biological Engineering Co,. Ltd. & 3.000 & Província de Jiangsum, China \\
\hline Shenzhen BrightChina Industrial Co., Ltd. & 10.000 & Shenzhen, China \\
\hline Tong-Jie-Liang Biomaterials Co. Ltd. & 1.000 & China \\
\hline
\end{tabular}


Os substratos utilizados na etapa de fermentação variam de acordo com a localidade da planta, dentre eles, encontrase a cana-de-açúcar, a beterraba, o trigo e o amido de milho. Nenhuma das empresas citadas acima possuem produção a partir de bagaço de cana ou qualquer outro tipo de biomassa lignocelulósica, porém, as empresas Cellulac, Purac e NatureWorks estão realizando pesquisas para viabilizar essa possibilidade ${ }^{14}$.

A capacidade produtiva a partir de bagaço de cana descrita no presente trabalho se encontra em patamar semelhante a algumas relatadas na Tabela 4. Esse tipo de processo é melhor aproveitado quando anexado à outra produção que apresenta, como resíduo, um tipo de biomassa lignocelulósica. Por exemplo, uma biorrefinaria que possui o etanol, a partir de caldo de cana-de-açúcar, como produto principal, pode aproveitar o processo de produção de ácido lático para empregar o bagaço de cana residual, aumentando, assim, o portfólio da instalação. Além disso, as correntes geradas como subproduto podem ser direcionadas para outras seções da biorrefinaria. O hidrolisado hemicelulósico pode ser aplicado a um processo fermentativo alternativo, que possui a xilose como substrato principal ${ }^{7}$.

\section{GERENCIAMENTO DE CENÁRIOS}

Por meio da ferramenta "Gerenciamento de Cenários" do software Microsoft Excel, foi possível testar o uso de diferentes composições de biomassa para o cálculo do balanço de massa e identificar como esse fator alteraria o rendimento global do processo. Essa ferramenta gera, como resposta, um relatório que contém os valores dos rendimentos alcançados. A Tabela 5 registra, resumidamente, os resultados obtidos para a lista completa de composições de diferentes tipos de biomassa lignocelulósicas relatadas por Silva ${ }^{3}$ e Souza ${ }^{4}$.

A média de rendimento entre as biomassas estudadas foi de $31 \%$, dentre elas se destacam os vegetais do gênero Eucalyptus, a palha de arroz e o bagaço de cana. O rendimento expressivo desses materiais quando comparado com os outros tipos de biomassa se deve ao alto teor de celulose presente em suas estruturas.
Tabela 5. Resultado do gerenciamento de cenários (biomassa).

\begin{tabular}{|c|c|c|}
\hline Cenários & Biomassa & Rendimento \\
\hline Cenário 1 & Farelo de cevada & $19,49 \%$ \\
\hline Cenário 2 & Sabugo de milho & $26,86 \%$ \\
\hline Cenário 3 & Folhas de milho & $31,86 \%$ \\
\hline Cenário 4 & Palha de arroz & $36,86 \%$ \\
\hline Cenário 5 & Palha de trigo & $28,64 \%$ \\
\hline Cenário 6 & Palha de sorgo & $28,81 \%$ \\
\hline Cenário 7 & Casca de aveia & $25,85 \%$ \\
\hline Cenário 8 & Eucalyptus grandis & $34,07 \%$ \\
\hline Cenário 9 & Eucalyptus globulus & $39,23 \%$ \\
\hline Cenário 10 & Bagaço de cana & $38,39 \%$ \\
\hline
\end{tabular}

\section{Conclusões}

$\mathrm{O}$ balanço de massa feito no presente trabalho indicou rendimento do processo de $38,39 \%$ em relação à biomassa inicial e a quantidade de produto gerado. Quando excluídas as frações hemicelulósicas e de lignina da biomassa, que não configuram como substrato para a produção de ácido lático, o rendimento foi de $84,74 \%$. A partir de 150 toneladas biomassa inicial, foram geradas 26,5 toneladas de hidrolisado celulósico, 24,5 toneladas de lignina e, como produto principal, 57,6 toneladas de ácido lático.

A planta proposta apresenta capacidade produtiva de 3731,4 toneladas de ácido lático por ano, similar a outras unidades produtivas relatadas pela bibliografia. Embora haja investimento por parte de algumas empresas, nenhuma das plantas encontradas relatam uso de biomassa lignocelulósica como matéria-prima. As análises feitas por meio da ferramenta "Gerenciamento de Cenários" sugerem que o rendimento do processo, ao utilizar bagaço de cana como matéria-prima, é 23,83\% maior que a média dos rendimentos obtidos a partir das espécies relatadas por Silva ${ }^{3}$.

O processo de produção proposto no presente trabalho apresenta bom rendimento em relação ao ácido lático, porém, é necessário realizar pesquisas relacionadas à 
viabilidade técnica e econômica para avaliar a rentabilidade e sua possível inserção em uma biorrefinaria.

\section{Referências}

1. Pereira Jr, N.; Bon, E. P. S.; Ferrara, M. A. Tecnologia de Bioprocessos. Séries em Biotecnologia. Rio de Janeiro, 2008.

2. Benevenuti, C. S. J. Prospecção Tecnológica da Produção de Ácido Lático no Contexto de Biorrefinaria: Tendências e Oportunidades. Dissertação de Mestrado, Apresentada ao Programa de PósGraduação em Tecnologia de Processos Químicos e Bioquímicos. Escola de Química. Universidade Federal do Rio de Janeiro. Rio de Janeiro, 2016.

3. Silva, M. G.; Júnior, J. L. S.; Júnior, C. R. T. P. Produção De Etanol De Segunda Geração: Uma Revisão. Pensamento Plural: Revista Científica da UNIFAE, v. 4, n. 2, 2010.

4. Souza, V. M. Z. Desenvolvimento de Novas Metodologias para o Pré-Tratamento e Hidrólise do Bagaço de Cana para a Produção de Etanol Celulósico. UNB. Monografia de Graduação em Engenharia de Energia. 2014.

5. Betancur, G.J.V.; Pereira Jr., N. Sugar Cane Bagasse as Feedstock for Second Generation Ethanol Production. Part I: Diluted Acid Pretreatment Optimization. Electronic Journal of Biotechnology 13 (3), 2010

6. Fernandes, D. M.; Braga Jr, R. A. Concepção de uma Planta de Etanol de Segunda Geração Associada a uma Planta de Primeira Geração Estabelecida. Orientador: Nei Pereira Jr. Escola de Química - Universidade Federal do Rio de Janeiro, 2016.

7. Schlittler, L. A. F. S. Biomassas e Biorrefinarias. Rio de Janeiro. 2007.

8. Rezende, C. A. et al. Chemical and Morphological Characterization of Sugarcane Bagasse Submitted to a Delignification Process for Enhanced Enzymatic Digestibility. Biotechnology for Biofuels, V. 4, N. 1, P. 54, 2011.

9. Méndez Arias, J. et al. Design of an Enzyme Cocktail Consisting of Different Fungal Platforms for Efficient Hydrolysis of Sugarcane Bagasse: Optimization and Synergism Studies. Biotechnology Progress, V. 32, N. 5, P. 1222-1229, 2016.

10. Kim, Y. H.; Moon, S. Lactic Acid Recovery from Fermentation Broth Using One Stage Electrodialysis. Journal of Chemical Technology and Biotechnology, V. 76, N. 2, P. 169-178, 2001.

11. Moraes, A. O.; Ramirez, N. I. B.; Pereira Jr, N. Evaluation of the Fermentation Potential of Pulp Mill Residue to Produce D(-)-Lactic Acid by Separate Hydrolysis and Fermentation Using Lactobacillus Coryniformis Subsp. Torquens. Applied Biochemistry and Biotechnology. Springer Science+Business Media New York. 2016.
12. Datta, R.; Henry, M. Lactic Acid: Recent Advances in Products, Processes and Technologies-A Review. Journal of Chemical Technology and Biotechnology, V. 81, N. 7, P. 1119-1129, 2006.

13. Ogeda, T. L.; Petri, D. F. Hidrólise Enzimática de Biomassa. Química Nova, V. 33, N. 7, P. 1549-1558, 2010.

14. Biddy, M. J.; Scarlata, C.; Kinchin, C. Chemicals from Biomass: A Market Assessment of Bioproducts with Near-Term Potential. National Renewable Energy Laboratory (NREL). v. 10, p. 1244312, 2016.

\section{Mateus K. Rodrigues, Michelle Reich, Flávia D. Pimenta. \& Marta C. Picardo*}

Centro de Tecnologia da Indústria Química e Têxtil (Faculdade SENAI CETIQT), Rua Magalhães Castro, 174, Riachuelo, CEP: 20961-020 - Rio de Janeiro, RJ, Brasil.

*E-mail: mcpicardo@cetiqt.senai.br 